\title{
Epidemiology of infectious syphilis in Singapore
}

\author{
T THIRUMOORTHY, C T LEE, AND K B LIM
}

From Middle Road Hospital, Singapore

SUMMARY The incidence of early infectious syphilis in Singapore rose from 8.7 per 100000 in 1980 to 25 per 100000 in 1984 . In this epidemiological study of 100 patients with early syphilis, 70 were men, the mean age was 31.7 (range 17 to 68) years, 25 patients had primary syphilis, 47 secondary syphilis, and the remaining 28 had early latent syphilis. Female prostitutes were cited as sources of infection by 46 and homosexual contacts by 11 . Reduced herd immunity, decreased use of penicillin, greater population movement, and decreased surveillance and awareness have contributed to this rise in infectious syphilis.

\section{Introduction}

The widespread use of penicillin after the second world war resulted in the dramatic decrease in the incidence of treponematosis throughout the world. Early syphilis decreased sharply in England and Wales and the United States of America from 1947 to 1974. From 1975 onwards there was a slight increase of early syphilis in both the United States and the United Kingdom, mainly among homosexual men. The absolute number of reported cases of primary and secondary syphilis in the United States rose from 21656 in 1978 to 33673 in $1982^{1}$.

A similar sharp drop in infectious syphilis occurred in Singapore in the early 'fifties, hitting a trough in early 'sixties. This was followed by a slow rise to a peak in 1974. Then coincidentally, or as a result of the introduction of a medical scheme among prostitutes in 1976, the rate continued to fall to a lower trough in 1979. Since 1980 syphilis has re-emerged and its incidence has continued to rise over the past four years (table I).

This rising incidence in infectious syphilis stimulated us to embark on a study of its epidemiology. The purpose of the study was to collect epidemiological data of patients with infectious syphilis, to use the data to understand the dynamics of transmission, and to identify high risk groups.

\section{Patients and methods}

From February 1984 we interviewed (using a standard interview form) and examined 100 consecutive patients with early infectious syphilis seen at this hospital.

Address for repints: Dr C T Lee, Middle Road Hospital, 250 Middle Road, Singapore 0718, Republic of Singapore

Accepted for publication 21 July 1985

\section{Results}

SEX, AGE, AND RACE

Of the 100 patients, 70 were men and 30 women. Their mean age was 31.7 (range 17 to 68 ) years. The mean ages of men and women were similar. The 25-29 year old age group was most affected, and 47 of the patients were between 20 and 29 .

Of the study population, 68 were Chinese, 13 Malays, 11 Indians, and eight other races. These numbers are consistent with the proportion of races of patients attending this hospital for all sexually transmitted diseases (STD).

\section{MARITAL STATUS}

Of the study population, 56 (46 men, 10 women) were single, 42 (24 men, 18 women) married, and two separated.

\section{OCCUPATION}

Semiskilled, unskilled, and armed forces personnel contributed 46 of the cohort. Twenty patients were

TABLE I Incidence of early syphillis in Singapore in 1974-84

\begin{tabular}{|c|c|c|c|c|}
\hline \multirow[b]{2}{*}{ Year } & \multicolumn{2}{|c|}{$\begin{array}{l}\text { Primary and secondary } \\
\text { syphilis }\end{array}$} & \multicolumn{2}{|c|}{ Early infectious syphilis } \\
\hline & $\begin{array}{l}\text { No of } \\
\text { cases }\end{array}$ & $\begin{array}{l}\text { Incidence } \\
\text { per } 1000001\end{array}$ & $\begin{array}{l}\text { No of } \\
\text { cases }\end{array}$ & $\begin{array}{l}\text { Incidence } \\
\text { per } 100000\end{array}$ \\
\hline $\begin{array}{l}1974 \\
1975 \\
1796 \\
1977 \\
1978 \\
1979 \\
1980 \\
1981 \\
1982 \\
1983 \\
1984\end{array}$ & $\begin{array}{r}306 \\
367 \\
176 \\
99 \\
113 \\
77 \\
155 \\
269 \\
295 \\
239 \\
328\end{array}$ & $\begin{array}{r}13.7 \\
16.2 \\
7.6 \\
4.3 \\
4.8 \\
3.2 \\
6.4 \\
11.0 \\
11.9 \\
9.5 \\
13.1\end{array}$ & $\begin{array}{l}363 \\
428 \\
201 \\
131 \\
142 \\
107 \\
209 \\
362 \\
435 \\
461 \\
626\end{array}$ & $\begin{array}{r}16.2 \\
18.9 \\
8.8 \\
5.6 \\
6.0 \\
4.5 \\
8.7 \\
14.8 \\
17.6 \\
18.4 \\
25.0\end{array}$ \\
\hline
\end{tabular}


prostitutes, seven of whom were male prostitutes. The small number (four) of professional and semiprofessionals may reflect a different disease pattern in such people or their preference for seeking private medical advice.

MODE OF PRESENTATION AND STAGE OF THE DISEASE Diagnosis was by serology only in 36 patients, who had no clinical evidence of treponemal infection; 31 patients presented with a skin rash and 29 with genital ulceration. Primary syphilis was diagnosed in 25, secondary in 47 , and early latent syphilis in 28 patients. The discrepancy between the number of cases detected by serology (36) and the number of patients with early latent syphilis (28) highlights the fact that patients may not realise the importance of the signs and symptoms. This was especially true among the prostitutes. Early latent syphilis was diagnosed in 11 of the 20 prostitutes, which suggested that they had been infectious for about three months before their infecton was detected; seven had secondary syphilis and two had primary syphilis at the time of diagnosis.

\section{SOURCE SEXUAL CONTACTS}

Table II shows the sexual contacts cited as sources of early syphilis: 46 patients named female prostitutes, all 20 prostitutes named clients, and 15 women named their husbands as the source. Homosexual contacts (paid or casual) accounted for 11 infections. This study confirms that prostitutes contribute to a dynamic pool and act as intermediaries in the transmission of syphilis.

Eighty one of all infections were acquired in Singapore. Prostitutes, however, constantly move between Singapore, Malaysia, and Thailand.

\section{DYNAMICS OF TRANSMISSION}

To study the dynamics of transmission, five major groups were chosen. The first consisted of the single men aged predominantly 19 to 35 who had semiskilled, unskilled, or armed forces occupational backgrounds. There were 39 single men (excluding the seven male prostitutes), $33(85 \%)$ whom acquired their infections from female prostitutes, five from casual

TABLE II Sexual contacts cited as sources of infection by 100 patients with early syphilis

\begin{tabular}{lc}
\hline Source cited & No \\
\hline Female prostitute & 46 \\
Client & 20 \\
Husband & 15 \\
Casual contact & 8 \\
Wife & 5 \\
Male prostitute & 2 \\
Casual homosexual & 2 \\
Massage or bar girl & 2 \\
Total & 100 \\
\end{tabular}

sexual contacts, and four from homosexual sources.

The second group consisted of prostitutes. All 20 in the study population had acquired the disease from their clients. Clients are always nameless and elusive, and contact tracing is thus almost impossible. Seven male prostitutes compared with 13 female prostitutes was a high proportion, as there were fewer than 200 male prostitutes and more than 3000 female prostitutes.

The third group consisted of the 24 married men, 17 of whom had acquired the disease from prostitutes and five from their wives. Seventeen $(71 \%)$ of the married men were aged over 40.

The fourth group consisted of married couples. Five men had acquired their infections from their wives and 15 women had acquired their infections from their husbands. What is important from the public health point of view is that eight of the 15 women were aged under 35 and therefore in the reproductive age group and at risk of transmitting the disease to a foetus.

The fifth group consisted of men infected homosexually. Seven male prostitutes had acquired the disease from clients, two single men had acquired it from male prostitutes, and two single men were infected during casual homosexual contact. All 11 had practised anal intercourse, the prostitutes having been passive and the other four men active. Bisexuality was not a feature of this group.

\section{Discussion}

This study shows that prostitution is still an important source and intermediary in the transmission of syphilis in Singapore. Of the 100 patients, 48 had acquired the disease from prostitutes and 20 were prostitutes. Prostitutes are offered routine three monthly serological examinations in Singapore. Seven of the 20 prostitutes who had secondary syphilis had not noticed any signs or failed to suspect the disease. A tightening of surveillance of both male and female prostitutes is necessary to control the rise in infectious syphilis.

Another reason put forward for the rise in infectious syphilis is the loss of herd immunity resulting from the clearance of non-venereal treponematosis. In addition, the decreased use of procaine penicillin injections in treating gonorrhoea because of the emergence of penicillinase producing strains of Neisseria gonorrhoeae (PPNG) and the fear of anaphylaxis to penicillin may have resulted in the nonclearance of incubating syphilis (especially in prostitutes).

The movement of prostitutes and migrant labour between Singapore and its neighbouring countries has probably contributed to the rise in infectious syphilis. Nineteen infections were acquired outside Singapore, $14(29 \%)$ of the prostitutes cited as sources of infection were non-Singaporean, and 20 of the 100 patients 
studied were non-Singaporean.

The extensive use of treponemicidal antibiotics for other illnesses and prophylactic self treatment for STD are common in Singapore. In an earlier survey $60 \%$ of prostitutes used antibotic prophylaxis. ${ }^{2}$ This habit would tend to extend the incubation period and modify the clinical expression of the disease and would logically result in the patient not seeking treatment and becoming a source of infection.

The initial fall in the incidence of syphilis and its complications has led to a lowered awareness of the disease among physicians. At least 13 patients in this study who had consulted a doctor previously had been given an incorrect diagnosis.

Even before the penicillin era, syphilis in Western Europe showed a progressive decline punctuated by transitory increases of almost epidemic character associated with war, political and political unrest, and population movement. Since the use of penicillin, epidemics have not been seen, but similar factors will possibly continue to result in periodic recrudescence of syphilis within the human population. Greater surveillance and more vigilant control measures therefore need to be taken to prevent the continued rise in incidence of infectious syphilis.

\section{References}

1. Aral SO, Holmes KK. Epidemiology of sexually transmitted diseases. In: Holmes KK, Mårdh P-A, Sparling PF, Wiesner PJ. eds. Sexually transmitted diseases. New York: McGraw-Hill, 1984:127-41.

2. Goh CL, Meija P, Sng EH, Rajan VS, Thirumoorthy T. Chemoprophylaxis and gonococcal infections in prostitutes. Int J Epidemiol 1984;13:344-6. 